\title{
Transferência de imunidade passiva em bezerras alimentadas com colostro de vacas com mastite subclínica
}

\author{
Passive immunity transfer in calves fed with \\ colostrum from dams with subclinical mastitis
}

\author{
Renata Freitas Leite ${ }^{1}$, Camila Costa Baccili', Cynthia Pereira da Costa e Silva', Sylvia Marquart \\ Fontes Novo', Vinicius Alvim Passos Baldacim', Nilson Roberti Benites', Viviani Gomes ${ }^{1 *}$
}

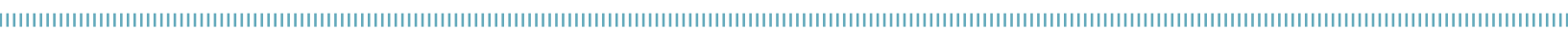

RESUMO: Este trabalho avaliou a influência da infecção bacteriana da glândula mamária $(\mathrm{GM})$ sobre a transferência de imunidade passiva (TIP) em bezerros recém-nascidos. Vacas holandesas $(n=13)$ foram observadas no momento da pariçáo e ordenhadas para a obtenção de forma asséptica das amostras de colostro $(\mathrm{n}=52)$ para os testes microbiológicos. Os recém-nascidos receberam 6 litros de colostro de uma ordenha nas primeiras 12 horas de vida, proveniente de suas respectivas mães. Amostras de sangue foram colhidas antes (D0) e após (D2) o manejo do colostro. A TIP foi avaliada por meio de testes bioquímicos, eletroforese e leucograma. Os bezerros foram distribuídos conforme a ausência (IB-) ou presença (IB+) de infecção mamária em pelo menos uma GM de suas respectivas mães. Todas as amostras de colostro $(n=52)$ foram negativas ao cultivo fúngico. Das 13 fêmeas, 8 $(61 \%)$ apresentaram crescimento bacteriano em $\geq 1$ quartos mamários. Considerando-se os quartos mamários, foi obtido isolamento bacteriano em 21,15\% (11/52), observando-se predomínio de espécies bacterianas do grupo Staphylococcus coagulase negativa. Não foram encontradas diferenças entre os parâmetros de acordo com os grupos experimentais. Em relação aos momentos, foi possível verificar aumento nos valores de proteína total, globulinas, atividade sérica da gama glutamiltransferase e fraçóes eletroforéticas beta e gamaglobulina após a ingestáo do colostro materno. A mastite subclínica não influencia a transferência de imunidade passiva em bezerros recém-nascidos da raça holandesa, avaliados por teste bioquímicos, eletroforese e leucograma.

PALAVRAS-CHAVE: eletroforese; testes bioquímicos; leucograma.

\begin{abstract}
This study evaluated the influence of intramammary infection under the passive immunity transfer in newborn calves. Holstein cows $(n=13)$ were monitored at delivery, and milked to obtain sterile colostrum samples $(n=52)$ for microbiological examination. The newborn calves received 6 liters of colostrum from their dams up to 12 hours after birth. Blood samples were harvested before (D0) and after (D2) colostrum feeding. The passive immune transfer was evaluated by biochemical tests, electrophoresis and leukogram. Calves were distributed according to absence (IB-) or presence (IB+) of mammary gland infection in one or more quarters. All colostrum samples $(n=52)$ were negative for fungal culture. Eight dams (8; 61\%) had bacterial growth in one or more mammary quarter. In relation to mammary gland unit, bacterial growth was observed in $21.15 \%$ (11/52) of the colostrum samples, with predominance of coagulase negative staphylococcal infections. Statistical differences were not found among variables according to the groups. According to the experimental moments, the evaluated parameters (total protein, albumin, globulins, GGT and beta and alpha electrophoretic) increased after colostrum intake. Subclinical mastitis did not influence the passive immune transfer in Holstein calves evaluated by biochemical tests, electrophoresis or leukogram.
\end{abstract}

KEYWORDS: electrophoresis; biochemical tests; leukogram. 


\section{INTRODUÇÃO}

A criação de bezerras é a fase crucial do sistema de produção leiteiro, por garantir o crescimento do rebanho e o aumento da produçáo, no entanto, o sucesso dessa atividade requer a implantaçáo de metas que permitam a sobrevivência, a sanidade e o desenvolvimento dos animais, admitindo-se índices de mortalidade e morbidade inferiores a 5 e $10 \%$, respectivamente, do nascimento ao desmame. Nesse contexto, o manejo do colostro é prioridade máxima, por conta das elevadas taxas de morbidade ( $\geq 22 \%$ ) em bezerras com falha da transferência de imunidade passiva (DCHA, 2013).

Bezerras recém-nascidas são agamaglobulinêmicas ao nascimento e necessitam de sucessivas exposiçôes aos patógenos para maturação imune, que se completa na puberdade (KAMPEN et al., 2006). Nesse período, a imunidade passiva adquirida pela ingestáo do colostro é fundamental para a proteção dos bovinos jovens nos primeiros meses de vida (BARRINGTON; PARRISH, 2001).

O colostro bovino contém elementos solúveis e celulares biologicamente ativos, sendo a IgG1 o principal componente imune transferido da circulação para a glândula mamária pelo mecanismo seletivo denominado de colostrogênese (WATSON, 1980). Essa imunoglobulina protege os bezerros especialmente pela sua capacidade de opsonização, neutralização e intensificação do mecanismo de citotoxicidade celular dependente de anticorpos (BIBURGER et al., 2014).

O direcionamento do sistema imune da glândula mamária (GM) ao neonato no período de colostrogênese pode ser desfavorável à sua própria proteção (GOMES et al., 2014). O periparto é marcado por elevadas taxas de infecção mamária (NEWMAN et al., 2009), sobretudo aquelas provocadas por Staphylococcus coagulase negativa e Streptococcus agalactiae. Nesse período, o risco para desenvolvimento de mastite é seis vezes mais elevado do que na lactaçáo. Além disso, a reagudização de processos inflamatórios oriundos da lactaçáo anterior pode ser evidenciada no pós-parto imediato (DINGWELL et al., 2002; RAJALA-SCHULTZ et al., 1999; ODENSTEN et al., 2007).

A presença de bactérias na GM durante o período de colostrogênese resulta em resposta inflamatória com alteraçôes na permeabilidade vascular, extravasamento de proteínas inflamatórias e diapedese de leucócitos polimorfonucleares. A evoluçáo desse processo pode causar a perda de tecido secretor, com impacto no volume e na qualidade do colostro produzido (MAUNSELL et al., 1998).

O impacto da mastite para a saúde e o crescimento das bezerras é pouco conhecido e controverso (FERDOWSI et al., 2009). MAUNSELL et al. (1998) encontraram menor volume e massa de IgG 1 no colostro de vacas com mastite, e FERDOWSI et al. (2009) verificaram menor concentração de proteína sérica em bezerros de máes com elevada contagem de células somáticas (CCS).
SANTOS et al. (2013) não evidenciaram falha na transferência de imunidade passiva (TIP) em bezerras que receberam pool de colostro de vacas com mastite assintomática ou sintomática. Observação semelhante foi encontrada por LAVEN et al. (2012), que não constataram diferenças na TIP em bezerras nascidas de vacas tratadas ou náo com selante de teto no pré-parto, prática adotada para prevenir a mastite durante o período seco.

A importância do manejo do colostro, a elevada incidência de mastite no periparto e a divergência entre os resultados apresentados anteriormente apontam para a realização de estudos para a definiçấo de uma questáo prática de manejo aplicável à rotina da criação de bezerras.

A hipótese desta pesquisa foi que a infecção mamária no pós-parto altera a composição do colostro bovino, comprometendo a transferência passiva de fatores imunes aos recém-nascidos. O objetivo desta investigaçáo consistiu em avaliar a influência da infecção bacteriana da glândula mamária no status imunitário dos recém-nascidos após a ingestão do colostro.

\section{MATERIAL E MÉTODOS}

Esta pesquisa foi aprovada pelo Comitê de Ética no Uso de Animais da Faculdade de Medicina Veterinária e Zootecnia da Universidade de São Paulo (USP) (Protocolo n. ${ }^{\circ}$ 2.305/11).

Foram selecionadas 13 fêmeas bovinas gestantes da raça holandesa preta e branca e seus respectivos conceptos, distribuídos em dois grupos experimentais conforme os resultados obtidos no exame bacteriológico e micológico do colostro: com infecção em $\geq 1 \mathrm{GM}(\mathrm{IB}+, \mathrm{n}=8)$ ou sem infecção mamária (IB-, $\mathrm{n}=5)$.

As vacas gestantes foram acompanhadas no último mês de gestaçáo e monitoradas a cada duas horas nos períodos diurno e noturno, com o objetivo de separar os bezerros das mães antes da mamada de colostro. Após a parição, as vacas eram encaminhadas para a sala de ordenha para coleta asséptica das amostras de colostro. Inicialmente foi realizada a lavagem dos tetos com solução de hipoclorito a $2 \%$, seguida de secagem com papel toalha individual. Por fim, realizaram-se a desinfecção do teto pela fricção de algodáo embebido em soluçấo de álcool $70 \%$ e a coleta das amostras pertencentes à fração intermediária de colostro para o exame microbiológico.

A primeira alíquota obtida foi semeada em placas de Petri contendo meio de ágar sangue de carneiro (5\%) e ágar Sabouraud, respectivamente mantidas a $37^{\circ} \mathrm{C}$ por 24 a 72 horas e à temperatura ambiente por 10 dias. As bactérias foram caracterizadas de acordo com as características de cultivo, morfotintoriais e bioquímicas, utilizando kits comerciais (RapID ${ }^{\mathrm{TM}}$ Staph Plus System, Thermo Scientific, Waltham, MA, EUA) (LENNETTE et al., 1985; KRIEG; HOLT, 1994; MURRAY et al., 1999). As culturas consideradas positivas 
foram as que apresentaram crescimento de pelo menos três colônias idênticas. Amostras com crescimento de mais de três cepas bacterianas diferentes foram consideradas contaminadas (NMC, 1999).

Os recém-nascidos foram alimentados com seis litros de pool de colostro fresco de primeira ordenha, proveniente de suas respectivas máes. Os litros foram divididos em 2 alimentaçôes de 3 litros cada, com intervalo de 6 horas, fornecidos nas primeiras 12 horas de vida.

Obtiveram-se amostras de sangue dos bezerros em tubos com ácido etilenodiamino tetracético (EDTA) e sem anticoagulante. As coletas das amostras foram feitas antes (D0) e depois da ingestão do colostro (D2).

O número total de leucócitos sanguíneos foi determinado por sistema automatizado (ABC Vet, $\mathrm{ABX}^{\circledast}$, Irvine, $\mathrm{CA}, \mathrm{EUA}$ ), associado à contagem diferencial dos leucócitos por metodologia manual pela diferenciação das células de acordo com o seu padrão morfológico.

A avaliação qualitativa da concentração de imunoglobulinas no sangue dos bezerros foi feita por meio do TSZ, utilizando-se solução de sulfato de zinco $\left(\mathrm{ZnSO}_{4} \cdot 7 \mathrm{H}_{2} \mathrm{O}\right)$ a $350 \mathrm{mg} / \mathrm{L}$, segundo procedimentos estabelecidos por HUDGENS et al. (1996).

As provas bioquímicas para determinação dos teores de proteína sérica total (PT), albumina (ALB) e atividade sérica da gama glutamiltransferase (GGT) ocorreram em aparelho automático (RX Daytona, Randox ${ }^{\circledR}$, Dublin, Irlanda), mediante kits comerciais, em conformidade com as recomendaçôes do fabricante.

Para o fracionamento das proteínas séricas foi realizada a migração eletroforética em fitas de acetato de celulose, por intermédio das técnicas modificadas de FRIEDMAN (1961) e KREMERS et al. (1967). Desenvolveram-se a leitura e interpretaçáo do fracionamento eletroforético em densitômetro para eletroforese com marcação manual das diferentes fraçôes proteicas (alfaglobulinas, betaglobulinas e gamaglobulinas), e avaliaram-se as curvas geradas segundo KANEKO (2008).

Foi realizada análise descritiva dos resultados obtidos no exame microbiológico do colostro e TSZ do soro. Os demais dados foram testados quanto à aderência à distribuição normal pelo teste de Shapiro-Wilk, constatando-se que a maioria das variáveis apresentou distribuição normal. Foram calculadas as médias ( \pm desvios padrão) dos parâmetros, e detectaram-se as diferenças estatísticas entre os grupos (IB+ e IB-) pelo teste $t$ de Student para amostras independentes. A comparação das médias antes da ingestão do colostro (D0) e após (D2) foram determinadas pelo teste $t$ de Student para amostras dependentes. Todos os testes foram considerados significativos quando $\mathrm{p}<0,05$.

Eosinófilos e neutrófilos bastonetes não indicaram distribuição paramétrica. As medianas e quartis estão em gráficos do tipo boxplot.

\section{RESULTADOS}

Das 13 vacas avaliadas, $8(61,54 \%)$ apresentaram isolamento bacteriano no colostro proveniente de $\geq 1$ dos quartos mamários. Destas, a maioria das vacas $(\mathrm{n}=6)$ apontou crescimento bacteriano em apenas 1 quarto mamário $(46,15 \%)$ e 2 delas em 2 ou 3 quartos mamários (15,38\%). Considerando-se os quartos, foi obtido isolamento bacteriano em $21,15 \%$ (11/52) das amostras avaliadas, observando-se predomínio de espécies bacterianas do grupo Staphylococcus coagulase negativa

Tabela 1. Espécies bacterianas isoladas do colostro bovino de vacas holandesas no periparto.

\begin{tabular}{|lcc|}
\hline Identificação das mães & Quarto mamário & Espécies bacterianas \\
\hline 1.406 & $\mathrm{AD}$ & S. capitis ss capitis e S. schleiferi \\
\hline 1.288 & $\mathrm{PE}$ & Staphylococcus warneri \\
\hline 1.265 & $\mathrm{AE}$ & Staphylococcus hyicus \\
\hline 4.453 & $\mathrm{AD}$ & S. chromogenes e S. schleiferi \\
\hline 1.241 & $\mathrm{AE}$ & Streptococcus agalactiae \\
\hline 1.482 & $\mathrm{AE}$ & Staphylococcus saprophyticus e Streptococcus dysgalactiae \\
\hline 1.459 & $\mathrm{AE}$ & Streptococcus dysgalactiae \\
\hline 1.485 & $\mathrm{AE}$ & Staphylococcus chromogenes \\
\hline & $\mathrm{PD}$ & S. schleiferi e Staphylococcus chromogenes \\
\hline
\end{tabular}

$\mathrm{AD}$ : quarto anterior direito; $\mathrm{PE}$ : quarto posterior esquerdo; $\mathrm{AE}$ : quarto anterior esquerdo; $\mathrm{PD}$ : quarto posterior direito. 
(SCN) (Tabela 1). Não houve crescimento fúngico nas amostras analisadas.

Os bezerros recém-nascidos (12/13) que receberam pool de colostro proveniente de GM com ou sem infecção bacteriana demonstraram reação negativa na prova de TSZ antes da ingestão do colostro (D0) e reaçóes positivas em D2, com exceção de apenas um bezerro do grupo $\mathrm{IB}_{+}$, que apresentou prova positiva no D0.

Os resultados obtidos para os dois grupos de bezerros que ingeriram pool de colostro proveniente de quartos sem (IB-) ou com infecção mamária (IB+) estão nas Tabelas 2 e 3 e na
Figura 1. Não foi possível detectar diferenças entre os grupos experimentais para os componentes do leucograma, parâmetros bioquímicos ou fraçóes eletroforéticas.

As diferenças entre os momentos antes da mamada de colostro (D0) e após a mamada (D2) para os parâmetros bioquímicos e fraçóes eletroforéticas apresentaram padrão clássico, verificando-se aumento dos teores de proteína total, globulinas, atividade sérica da GGT, beta e gamaglobulinas em 24-48 horas pós-nascimento ( $\mathrm{p} \leq 0,05)$ (Tabela 3). Apenas não se puderam detectar diferenças entre os momentos para os componentes do leucograma (Tabela 2 e Fig. 1).

Tabela 2. Médias e desvios padrão dos componentes do leucograma de bezerras holandesas antes (DO) e depois (D2) da ingestão de colostro oriundo de glândula mamária infectada (IB+) ou não infectada (IB-) com bactérias.

\begin{tabular}{|c|c|c|c|c|}
\hline Parâmetros & Momentos & $\begin{array}{l}\text { Glândula mamária infectada } \\
\text { (média } \pm \text { DP) }\end{array}$ & 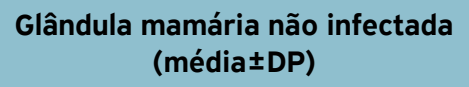 & Valor $\mathrm{p}$ \\
\hline \multirow{2}{*}{ Leucócitos $\left(x 10^{3} / \mu \mathrm{L}\right)$} & DO & $14,85 \pm 4,27$ & $15,45 \pm 6,86$ & 0,850 \\
\hline & D2 & $11,47 \pm 4,27$ & $16,07 \pm 3,13$ & 0,082 \\
\hline \multirow{2}{*}{ Neutrófilos $\left(\times 10^{3} / \mu \mathrm{L}\right)$} & DO & $7,64 \pm 3,81$ & $10,77 \pm 5,26$ & 0,247 \\
\hline & D2 & $5,93 \pm 3,85$ & $8,65 \pm 2,38$ & 0,225 \\
\hline \multirow{2}{*}{ Monócitos $\left(\times 10^{3} / \mu \mathrm{L}\right)$} & DO & $1,40 \pm 0,61$ & $0,95 \pm 0,57$ & 0,208 \\
\hline & D2 & $1,28 \pm 0,99$ & $1,44 \pm 1,00$ & 0,788 \\
\hline \multirow{2}{*}{ Linfócitos $\left(\times 10^{3} / \mu \mathrm{L}\right)$} & DO & $4,13 \pm 1,74$ & $2,94 \pm 1,27$ & 0,249 \\
\hline & D2 & $3,88 \pm 0,94$ & $5,26 \pm 2,84$ & 0,199 \\
\hline
\end{tabular}

DP: desvio padrão; DO: antes da ingestão de colostro; D2: após a ingestão de colostro. Diferenças entre os grupos avaliada pelo teste $t$ de Student para amostras independentes $(p \leq 0,05)$.

Tabela 3. Médias e desvios padrão dos parâmetros bioquímicos e frações eletroforéticas do soro de bezerras holandesas antes e depois da ingestão de colostro oriundo de glândula mamária infectada (IB+) ou não infectada (IB-) com bactérias.

\begin{tabular}{|c|c|c|c|c|}
\hline Parâmetros & Tempos & $\begin{array}{l}\text { Glândula mamária infectada } \\
\text { (média } \pm D P \text { ) }\end{array}$ & $\begin{array}{l}\text { Glândula mamária não infectada } \\
\text { (média } \pm \text { DP) }\end{array}$ & Valor $p$ \\
\hline \multirow{2}{*}{ Proteína total $(\mathrm{g} / \mathrm{dL})$} & DO & $4,21 \pm 0,25^{\mathrm{B}}$ & $4,13 \pm 0,83^{\mathrm{B}}$ & 0,796 \\
\hline & D2 & $6,88 \pm 0,97^{A}$ & $6,61 \pm 0,88^{A}$ & 0,645 \\
\hline \multirow{2}{*}{ Albumina (g/dL) } & DO & $2,79 \pm 0,14^{A}$ & $2,67 \pm 0,26^{A}$ & 0,301 \\
\hline & D2 & $2,45 \pm 0,18^{B}$ & $2,33 \pm 0,17^{\mathrm{B}}$ & 0,310 \\
\hline \multirow{2}{*}{ Globulinas (g/dL) } & DO & $1,41 \pm 0,19^{B}$ & $1,45 \pm 0,57^{\mathrm{B}}$ & 0,842 \\
\hline & D2 & $4,43 \pm 0,93^{A}$ & $4,27 \pm 1,02^{A}$ & 0,797 \\
\hline \multirow{2}{*}{ GGT (U/L) } & DO & $4,52 \pm 3,48^{\mathrm{B}}$ & $3,83 \pm 2,52^{B}$ & 0,730 \\
\hline & D2 & $334,37 \pm 162,81^{A}$ & $220,96 \pm 153,72^{A}$ & 0,264 \\
\hline \multirow{2}{*}{ Albumina (g/dL) } & DO & $2,19 \pm 0,21$ & $1,87 \pm 0,20$ & 0,027 \\
\hline & D2 & $2,05 \pm 0,22$ & $1,84 \pm 0,12$ & 0,120 \\
\hline \multirow{2}{*}{ Alfaglobulina $(\mathrm{g} / \mathrm{dL})$} & DO & $1,16 \pm 0,15$ & $1,07 \pm 0,13$ & 0,357 \\
\hline & D2 & $1,10 \pm 0,09$ & $1,10 \pm 0,09$ & 0,972 \\
\hline \multirow{2}{*}{ Betaglobulina ( $\mathrm{g} / \mathrm{dL}$ ) } & DO & $0,62 \pm 0,09^{A}$ & $0,54 \pm 0,16^{A}$ & 0,259 \\
\hline & D2 & $1,22 \pm 0,24^{B}$ & $1,17 \pm 0,09^{B}$ & 0,747 \\
\hline \multirow{2}{*}{ Gamaglobulina (g/dL) } & DO & $0,21 \pm 0,08^{\mathrm{B}}$ & $0,62 \pm 0,44^{\mathrm{B}}$ & 0,016 \\
\hline & D2 & $2,49 \pm 0,73^{A}$ & $2,48 \pm 0,73^{A}$ & 0,975 \\
\hline
\end{tabular}

DP: desvio padrão; DO: antes da ingestão de colostro; D2: após a ingestão de colostro. Letras diferentes na mesma coluna indicam diferenças estatísticas pelo teste $t$ de Student para amostras dependentes $(p \leq 0,05)$. As diferenças entre os grupos foram detectadas pelo teste $t$ de Student para amostras independentes $(p \leq 0,05)$. 

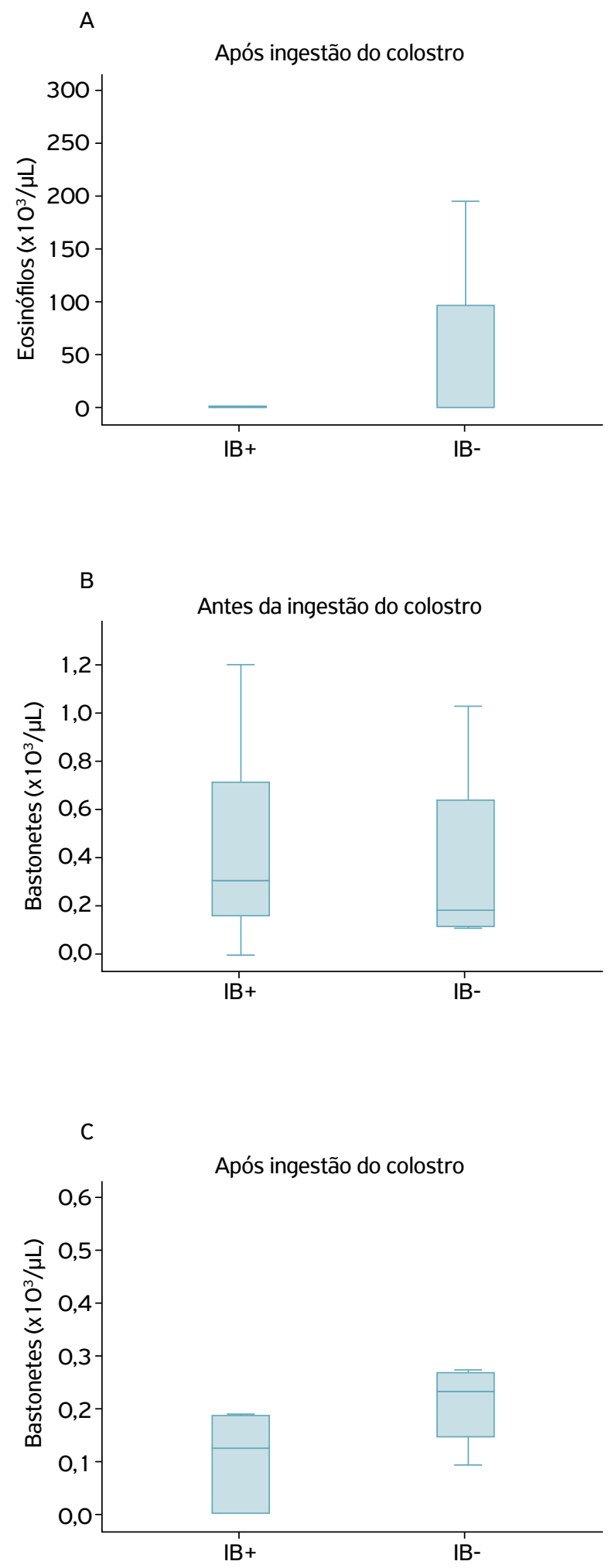

*Outlier. IB+: glândula mamária infectada; IB-: glândula mamária não infectada. Eosinófilos não foram detectados no antes da ingestão de colostro.

Figura 1. Valores medianos para os valores absolutos de eosinófilos e neutrófilos bastonetes antes (DO) e depois (D2) da ingestão de colostro oriundo de glândula mamária infectada $(\mathrm{IB}+)$ ou não infectada (IB-) com bactérias.

\section{DISCUSSÃO}

A sobrevivência de bezerras nas primeiras semanas de vida depende da imunidade passiva adquirida pela ingestão de colostro materno (BARRINGTON; PARRISH, 2001). O gerenciamento do manejo do colostro inclui a avaliaçấo da sua higiene e qualidade microbiológica, que pode ser afetada pela presença de infecção mamária no pós-parto imediato (FERDOWSI et al., 2009; JOHNSON et al., 2007). Além disso, a ausência de consenso sobre a infecção mamária e a qualidade do colostro motivaram a realização desta pesquisa.

A prevalência de infecção mamária observada aqui foi de 61,40 e $21,15 \%$, nessa ordem, considerando vacas e quartos mamários, causada especialmente por bactérias dos grupos Staphylococcus coagulase negativa e Streptococcus dysgalactiae, citadas na literatura como os principais patógenos envolvidos com os quadros de mastite manifestados no período de transição (DINGWELL et al., 2002; RAJALA-SCHULTZ et al., 2005; ODENSTEN et al., 2007). Essas bactérias são integrantes da microbiota da pele do aparelho mamário e provavelmente expressam seu potencial de virulência no pós-parto imediato por conta das adaptaçóes fisiológicas, metabólicas e imunológicas ocorridas nessa fase do ciclo produtivo (OLIVER; SORDILLO, 1988; PARK et al., 1992; GOFF; HORST, 1997).

A infecção pela bactéria Staphylococcus coagulase negativa da GM em vacas leiteiras durante o periparto é transitória, e a maioria dos animais não desenvolve mastite clínica (SILVA et al., 2014). Esse fato também foi observado na presente investigação, pois não foram relatados quadros ou tratamento de mastite clínica pelo produtor no pós-parto imediato.

Os resultados obtidos no TSZ, nas análises bioquímicas e na eletroforese permitem afirmar que o manejo de colostro adotado foi eficiente para a transferência de imunidade passiva aos neonatos.

A maioria das bezerras apresentou resultados negativos no teste de TSZ antes da ingestão do colostro em razão do status hipogamaglobulinêmico dos bezerros ao nascimento, decorrentes da placenta sinepiteliocorial das fêmeas bovinas (BARRINGTON; PARRISH, 2001). Apenas um animal avaliado apresentou reação positiva antes da mamada do colostro (D0), talvez pela infecçáo durante o período fetal, comumente causada pelo vírus da diarreia viral bovina (MARTIN et al., 2016).

$\mathrm{O}$ aumento dos valores de PT, globulinas e fraçóes eletroforéticas após a ingestão do colostro é consensual e ocorre pela passagem de imunoglobulinas provenientes do colostro pelo epitélio intestinal do bovino recém-nascido nas primeiras 24 horas de vida (WATSON, 1980). Os valores obtidos nesta pesquisa, nas provas bioquímicas, foram semelhantes aos encontrados por FEITOSA et al. (2001) para proteína total $(6,55 \mathrm{~g} / \mathrm{dL})$ e albumina $(2,61 \mathrm{~g} / \mathrm{dL})$ após a ingestão do colostro, porém a atividade sérica da enzima GGT foi menor do que aquela relatada pelo último autor citado $(702,45 \mathrm{U} / \mathrm{L})$. Em contrapartida, os valores da atividade sérica da GGT 
foram semelhantes aos valores (250-300 U/L) relatados por JEZEK et al. (2010). A forma de amamentação e o volume de colostro ingerido pelos bezerros podem explicar as diferenças obtidas. FEITOSA et al. (2001) avaliaram bezerros oriundos de diferentes fazendas, as quais provavelmente não adotavam o sistema de mamada controlada. Assim, as bezerras podem ter ingerido maior volume de colostro do que o estabelecido no delineamento experimental desta pesquisa.

Não foi possível observar diferenças entre os grupos de bezerros que ingeriram colostro proveniente de vacas com e sem infecção bacteriana, considerando as provas tradicionalmente empregadas para avaliação da transferência de imunidade passiva. Esse resultado é condizente com os achados de SANTOS et al. (2013), que não verificaram FTIP em bezerros com mastite assintomática ou sintomática. A vaca recém-parida geralmente é ordenhada no pós-parto imediato, sendo o pool do colostro oriundo dos quartos mamários fornecido aos recém-nascidos. Portanto, a mistura do colostro entre GM hígidas e infectadas pode resultar em qualidade imunológica adequadamente suficiente para a transferência dos fatores imunes necessários aos neonatos. É válido ressaltar que a maioria das vacas IB+ desta pesquisa apresentava infecção mamária em apenas um dos quartos, sem manifestação de quadro clínico de mastite.

FERDOWSI et al. (2009) encontraram menores concentraçóes de proteína total em bezerros alimentados com colostro, apresentando elevada CCS. Nesse caso, os referidos autores avaliaram a CCS no pool de colostro oferecido aos bezerros, e não amostras individuais. Esta pesquisa não avaliou o pool do colostro, e sim amostras individuais por quartos mamários.

A transferência de células maternas e a influência da infecção mamária mediante a análise do leucograma não puderam ser confirmadas, provavelmente porque se trata de um exame quantitativo e inespecífico, que sofre influência de outros fatores fisiológicos e ambientais aos quais os recém-nascidos são desafiados pós-nascimento (BENESI et al., 2012).

Dessa forma, pôde-se verificar similaridade entre os parâmetros bioquímicos, eletroforéticos e celulares nos grupos de bezerros que receberam colostro de mães sem e com infecção mamária no pós-parto imediato.

\section{CONCLUSÕES}

A mastite subclínica não influencia na transferência de imunidade passiva em bezerros recém-nascidos da raça holandesa, avaliados por teste bioquímico, eletroforese e leucograma.

\section{AGRADECIMENTO}

À Fundação de Amparo à Pesquisa do Estado de São Paulo (FAPESP) pela concessão de bolsa de iniciação científica (Processo FAPESP n.o 2011/20707-6) para a realização deste trabalho.
BARRINGTON, G.M.; PARISH, S.M. Bovine neonatal immunology. Veterinary Clinics of North America: Food Animal Practice, v.17, n.3, p.463-476, 2001.

BENESI, F.J.; TEIXEIRA, C.M.C.; LEAL, M.L.R.; LISBOA, J.A.N.; MIRANDOLA, R.M.S.; SHECAIRA, C.L.; GOMES, V. Leukograms of healthy Holstein calves within the first month of life. Pesquisa Veterinária Brasileira, v.32, n.4, p.352-356, 2012.

BIBURGER, M.; LUX, A.; NIMMERJAHN, F. How immunoglobulin G antibodies kill target cells: revisiting an old paradigm. Advances in Immunology, v.124, p.67-94, 2014.

DCHA - DAIRY CALF \& HEIFER ASSOCIATION. Dairy Calf $\odot$ Heifer Association Gold Standards II: production and performance standards established for Holstein calves, from birth to 6 months of age, across the United States. 2013. v.1. 2p.

DINGWELL, R.T.; DUFFIELD, T.F.; LESLIE, K.E;; KEEFE, G.P.; DESCOTEAUX, L.; KELTON, F.; LISSEMORE, K.D.; SCHUKKEN, Y.H.; DICK, P.; BAGG, R. The efficacy of intramammary tilmicosinat drying-off, and other risk factors for the prevention of new intramammary infections during the dry period. Journal of Dairy Science, v.85, p.3250-3259, 2002.
FEITOSA, F.LF;:BIRGEL, EH.; MIRANDOLA, R.M.S.;PERRI, S.H.V.Diagnóstico de falha de transferência de imunidade passiva em bezerros através da determinação de proteína total e de suas frações eletroforéticas, imunoglobulinas g e m e da atividade da gama-glutamiltransferase no soro sanguíneo. Ciência Rural, v.31, p.251-255, 2001.

FERDOWSI, E.; NIKKHAH, A.; RAHMANI, H.R.; MOHAMMAD ALIPOUR, M.; GHORBANI, G.R. Increased colostral somatic cell counts reduce pre-weaning calf immunity, health and growth. Journal of Animal Physiology and Animal Nutrition, v.94, p.628-634, 2009.

FRIEDMAN, H.S. A standardized procedure for serum protein electrophoresis on celulose acetate membrane strips. Clinica Chimica Acta, v.6, p.775-781, 1961.

GOFF, J.P., HORST, R.L. Physiological changes at parturition and their relationship to metabolic disorders. Journal of Dairy Science, v.80, p.1260-1268, 1997.

GOMES, V.; MADUREIRA, K.M.; SORIANO, S.; PONTES, G.N.; SILVA, B.T.; DELLA LIBERA, A.M.M.P.; BENESI, F.J. Release of hydrogen peroxide by phagocytes from bovine colostrums in the peripartum period. Acta Veterinaria BRNO, v.83, p.181-185, 2014. 
HUDGENS, K.A.R.; TYLER, J.W.; BESSER, T.E.; KRYTENBERG, D.S. Optimizing performance of a qualitative zinc sulfate turbidity test for passive transfer of immunoglobulin $\mathrm{G}$ in calves. American Journal of Veterinary Research, v.57, n.12, 1996.

JEZEK, J., NEMEC, M.; MALOVRH, T.; KLINKON, M. Indicators of passive immunity and health status of calves. Acta Veterinaria (Beograd), v.60, n.5-6, p.513-523, 2010.

JOHNSON, J.L.; GODDEN, S.M; MOLITOR, T.; AMES, T.; HAGMAN, $D$. Effects of feeding heat-treated colostrum on passive transfer of immune and nutritional parameters in neonatal dairy calves. Journal of Dairy Science, v.90, p.5189-5198, 2007.

KAMPEN, A.H.; OLSEN, I.; TOLLERSRUD, T.; STORSET, A.K.; LUND, A. Lymphocyte subpopulations and neutrophil function in calves during the first 6 months of life. Veterinary Immunology and Immunopathology, v.113, n.1-2, p.53-63, 2006.

KANEKO, J. J.; HARVEY, J.W.; BRUSS, M.L. Clinical biochemistry of domestic animals. 6. ed. New York: Academic Press, 2008. 904p.

KREMERS, B.; BRIERE, R.O.; BATASAKIS, J.G. Reflectance densitometry of cellulose acetate protein electrophoresis. American Journal of Medical Technology, v.33, p.28-34, 1967.

KRIEG, N.R.; HOLT, J.C. Bergey's manual of systematic bacteriology. 9. ed. Baltimore: Williams \& Wilkins Co., 1994. 787p.

LAVEN, R.R. Effect of use of teatseal ants at drying off on the uptake of colostral antibodies by calves, as estimated by measuring gamma-glutamyltransferase activity. New Zealand Veterinary Journal, v.60, n.1, p.47-49, 2012.

LENNETTE, E.M.; BALOWS, A.; HANSLER JR, W.J. Manual of clinical microbiology. 4. ed. Washington: American Society of Microbiology, 1985. 254p.

LINDBERG, A.L. Bovine viral diarrhea virus infections and its control: a review. The Veterinary Quarterly, v.25, p. 1-16, 2003.

MAUNSELL, F.P.; MORIN, D.E.; CONSTABLE, P.D.; HURLEY, W.L.; MCCOY, G.C.; KAKOMA, I.; ISAACSON, R.E. Effects of mastitis on the volume and composition of colostrum produced by Holstein cows. Journal of Dairy Science, v.81, p.1291-1299, 1998.
MURRAY, P.R.; BARON, E.J.; PFALLER, M.A.; TENOVER, F.C.; YOLKEN, R.H. Manual of clinical microbiology. 7. ed. Washington: American Society for Microbiology, 1999. 365p.

NATIONAL MASTITIS COUNCIL. Laboratory handbook on bovine mastitis. Arlington: National Mastitis Council, 1999. 208p.

NEWMAN, K.A.; RAJALASCHULTZ, P.J.; LAKRITZ, J.; DEGRAVES, F.J. Lactoferrin concentrations in bovine milk prior todryoff. Journal of Dairy Research, v.76, p.426-432, 2009.

ODENSTEN, M.O.; BERGLUND, B.; PERSSON WALLER, K.; HOLTENIUS, K. Metabolism and udder health at dry-off in cows of different breeds and production levels. Journal of Dairy Science, v.90, p.1417-1428, 2007.

OLIVER, S.P.; SORDILLO, L.M. Udder health in the periparturient period. Journal of Dairy Science, v.7 1, n.9, p.2584-2606, 1988.

PARK, Y.H.; FOX, L.K.; HAMILTON, M.J.; DAVIS, W.C. Bovine mononuclear leukocyte subpopulations in peripheral blood and mammary gland secretions during lactation. Journal of Dairy Science, v.75, n.4, p.998-1006, 1992.

RAJALA-SCHULTZ, P.J.; GROHN, Y.T.; MCCULLOCH, C.E.; GUARD, C.L. Effects of clinical mastitis on milk yield in dairy cows. Journal of Dairy Science, v.82, p.1213-1220, 1999.

SANTOS, G.G.F.; DESCHK, M.; SILVA, A.K.G.; POLO, T.S.; MARINHO, M.; PEIRÓ, J.R.; MENDES, L.C.N.; FEITOSA, F.L.F. Proteinograma sérico de bezerros recém-nascidos alimentados com colostro de vacas com mastite. Brazilian Journal of Veterinary Research Animal Science, v.50, n.3, p.188-197, 2013.

SILVA, C.P.C.; BALDACIM, V.A.P.; REIS, J.F.; NOVO, S.M.F.; SANTOS, O.; STRICAGNOLO, C.R.; HURLEY, D.J.; GOMES, V. Functional activity of neutrophils $\mathrm{CH} 138+$ in bovine colostrum and transition milk through natural exposure to bacterias. In: WORLD BUIATRICS CONGRESS, 27., Cairns, Austrália, 2014. Resumos. Cairns, 2014.

WATSON, D.L. Immunological functions of the mammary gland and its secretion - comparative review. Australian Journal Biological Science, v.33, p.403-422, 1980. 